\title{
(2) OPEN ACCESS \\ Gender, marital and educational inequalities in mid- to late-life depressive symptoms: cross-cohort variation and moderation by urbanicity degree
}

\author{
Milagros A Ruiz (10, ${ }^{1}$ Marielle A Beenackers, ${ }^{2}$ Dany Doiron, ${ }^{3}$ Asli Gurer, ${ }^{3}$ Aliou Sarr, ${ }^{3}$ \\ Nazmul Sohel, ${ }^{4,5}$ Erik J Timmermans (10, ${ }^{6}$ Rita Wissa, ${ }^{3}$ Basile Chaix ${ }^{7}$ \\ Martijn Huisman, ${ }^{6,8}$ Steinar Krokstad $\mathbb{B}^{1},{ }^{9,10}$ Ruzena Kubinova, ${ }^{11}$ Sofia Malyutina, ${ }^{12,13}$ \\ Parminder Raina, ${ }^{4,5}$ Abdonas Tamosiunas, ${ }^{14,15}$ Frank J van Lenthe, ${ }^{2,16}$ Martin Bobak ${ }^{1}$
}

\begin{abstract}
- Supplemental material is published online only. To view please visit the journal online (http://dx.doi.org/10.1136/ jech-2020-214241)
\end{abstract}

For numbered affiliations see end of article.

\section{Correspondence to} Milagros A Ruiz, Research Department of Epidemiology and Public Health, University College London, 1-19 Torrington Place, London WC1E 7HB, UK; m.a.ruiz@ucl.ac.uk

Received 3 April 2020

Revised 13 July 2020

Accepted 28 July 2020

Published Online First

5 November 2020

\begin{abstract}
Background Although ageing populations are increasingly residing in cities, it is unknown whether depression inequalities are moderated by urbanicity degree. We estimated gender, marital and educational inequalities in depressive symptoms among older European and Canadian adults, and examined whether higher levels of urbanicity, captured by population density, heightened these inequalities.

Methods Harmonised cross-sectional data on 97826 adults aged $\geq 50$ years from eight cohorts were used. Prevalence ratios (PRs) were calculated for probable depression, depressed affect and depressive symptom severity by gender, marital status and education within each cohort, and combined using random-effects metaanalysis. Using a subsample of 73123 adults from six cohorts with available data on population density, we tested moderating effects measured by the number of residents per square kilometre.
\end{abstract}

Results The pooled PRs for probable depression by female gender, unmarried or non-cohabitating status and low education were 1.48 (95\% Cl 1.28 to 1.72$)$, $1.44(95 \% \mathrm{Cl}$ 1.29 to 1.61$)$ and $1.29(95 \% \mathrm{Cl} 1.18$ to 1.41$)$, respectively. PRs for depressed affect and high symptom severity were broadly similar. Except for one Dutch cohort with findings in an unexpected direction, there was no evidence that population density modified depressive symptom inequalities.

Conclusions Despite cross-cohort variation in gender, marital status and educational inequalities in depressive symptoms, there was weak evidence that these inequalities differed by levels of population density.

\section{INTRODUCTION}

Globally, years lived with disability owing to depressive disorders increased by 38\% from 1990 to $2010 .^{12}$ Major depressive disorder (MDD) occurs in $1-5 \%$ of adults aged $\geq 65$ years worldwide; and clinically significant depressive symptoms, which fall below the diagnostic criteria for MDD, afflict $15 \%$ of adults aged $\geq 65$ years. $^{2}$ Being female, unmarried/divorced/widowed, and having low education are potent risk factors for depressive disorders in later life. ${ }^{3-5}$ Prior studies, however, have shown that these depression inequalities vary between countries, ${ }^{6-8}$ which may be attributable to differences in social environments.
Parallel to the rise of mid- to late-life depression, the share of the global population living in cities rose from $43 \%$ to $54 \%$ from 1990 to 2014 , and will reach $66 \%$ by 2050 . As the pace of urbanisation has accelerated, mental disorders have increased among city dwellers. ${ }^{9}$ Recent findings indicate that depression risk is $44 \%$ higher in older urban adults than in rural counterparts in developed countries. ${ }^{2}$ The impact of these urban-rural differences are considerable, since $43 \%$ of older adults from developed societies currently reside in cities. ${ }^{10}$

Gender, marital status and education, on the one hand, ${ }^{3-5}$ and urban living, ${ }^{2}$ on the other hand, have been extensively studied in relation to mid- to latelife depression. Despite the growing importance of the urbanised world for ageing populations, to our knowledge, no study has examined whether urbanicity, defined as the presence of conditions specific to urban areas, ${ }^{9}$ interacts with older adults' position in society to influence their mental health. First, older people's safety in cities, where injuries and crime are rampant, ${ }^{9}$ is associated with psychological distress, but effects appear twice as high in older women compared to older men. ${ }^{11}$ Second, social relationships, which protect against mid- to late-life depression, appear weaker at higher levels of population density. Social cohesion and collective efficacy seem weaker in more dense communities, and older adults living in these areas tend to have more numerous, but less intimate, personal relationships. ${ }^{12}$ The social integration of older singletons and widowers may be poorer in more urbanised settings. ${ }^{8}$ Third, although dense cities often have better service environments than smaller cities and non-urban areas, ${ }^{9}$ health and social services can often be overburdened, which could unequally affect socially disadvantaged adults.

Since mid- to late-life depression inequalities in different settings may vary by urbanicity degree, we measured cross-sectional associations of gender, marital status and education with depressive symptoms among older adults in Europe and Canada, and tested whether population density, a marker of urbanicity, ${ }^{9}$ modified the hypothesised inequalities. As urbanicity refers to the conditions which are far more predominant in urban areas than non-rural areas, ${ }^{9}$ population density is often used to examine the impact of urban living on health. ${ }^{13}$ 


\section{METHODS}

\section{Study populations}

Harmonised data from the Promoting Mental Well-being in the Ageing Population: Determinants, Policies and Interventions in European Cities (MINDMAP) project from eight cohort studies ${ }^{14}$ were analysed (in descending analytic sample size): the Canadian Longitudinal Study on Aging ${ }^{15}$ (CLSA, $n=45782$ ); the Nord-Trøndelag Health Study ${ }^{16}$ (HUNT, $\mathrm{n}=23$ 571); the Russian (HAPIEE-RU, $\mathrm{n}=7766$ ), Czech (HAPIEE-CZ, $\mathrm{n}=6726$ ) and Lithuanian (HAPIEE-LT, $n=6239$ ) cohorts from the Health, Alcohol and Psychosocial factors In Eastern Europe multicountry study ${ }^{17}$; the Residential Environment and CORonary heart Disease study ${ }^{18}$ (RECORD, $\left.n=3706\right)$; and the Longitudinal Aging Study Amsterdam ${ }^{19}$ first (LASA-1, $\mathrm{n}=3041$ ) and second (LASA-2, $\mathrm{n}=995$ ) cohorts.

The analytic sample $(n=97826)$ comprised adults aged $\geq 50$ years with complete data on depressive symptoms, gender, marital status and education plus covariates at Wave 1 for all cohorts except HUNT (Wave 2). An analytic subsample ( $\mathrm{n}=73$ 123) also comprised adults aged $\geq 50$ years with the aforementioned data plus information on population density from six studies at Wave $1 \quad(\mathrm{CLSA}=45$ 782; RECORD=3706), Wave 2 (HAPIEE$\mathrm{CZ}=1241$; LASA-2=835), Wave 3 (HUNT=20 566) or Wave 5 (LASA-1 =993). Selection criteria of both samples are depicted in flow diagrams (online supplemental figure S1).

\section{Depressive symptoms}

Four depression screening scales designed for general populations, including older adults, were administered across cohorts: the Center for Epidemiological Studies Depression (CES-D) scale-10item version (CLSA-COP, ${ }^{20}$ CLSA-TRA $^{20}$ and HAPIEE-LT ${ }^{21}$ ) and the CES-D 20-item version ${ }^{22}$ (HAPIEE-RU, HAPIEE-CZ, LASA-1 and LASA-2), the 7-item depression sub-scale from the Hospital Anxiety and Depression Scale ${ }^{23}$ (HADS-D) (HUNT) and the 13item Questionnaire of Self-Evaluated Depressive Symptomatology $^{24}$ (QD2A) (RECORD). Depressive symptom scores were used to derive study-specific measures of probable depression and depressive symptom severity. Probable depression was based on whether participants had elevated depressive symptoms at or above the threshold for the specific CES-D 10, ${ }^{20}$ CESD 20, ${ }^{25}$ HADS-D ${ }^{23} 26$ and QD2A ${ }^{24}$ scores. Since higher scores are intended to reflect higher depression risk, scores were split into study-specific tertiles denoting low, moderate or high severity. Depressed affect was based on whether participants reported feeling sad, depressed or downhearted. Online supplemental table S1 reports the retrospective data harmonisation performed to derive these outcomes.

\section{Covariates}

Covariates included age, age squared, gender, marital or cohabitation status, and education classified as high (postsecondary nontertiary or higher, ISCED 4-8) or low (upper secondary or lower, ISCED 0-3), using the International Standard Classification of Education (ISCED 2011). ${ }^{27}$ Self-rated health was also included as a confounder to control for potential country differences in reporting behaviour. ${ }^{28}$ Population density of participants' residence, defined as the number of residents per square kilometre, was matched the studies' examination period as closely as feasibly possible: 2016 data were linked to CLSA Wave 1 (2010-2015), 2011 data to HAPIEE-CZ Wave 2 (2006-2008), 2009 data to RECORD Wave 1 (2007-2008) and 2006 data to HUNT Wave 3 (2006-2008) as well as LASA-1 Wave 5 and LASA-2 Wave 2 which were concurrently examined in 2005-2006. Population density data were provided by Statistics Canada (CLSA), Statistics Netherlands (LASA-1 and LASA-2), Statistics Norway (HUNT), the Czech Statistical Office (HAPIEE-CZ) and the National Institute of Statistics and Economic Studies (RECORD), which were calculated at the census subdivision level (CLSA), municipality level (HUNT and RECORD) and neighbourhood level (in the remaining cohorts).

\section{Statistical analyses}

Prevalence proportions of depressive symptoms were directly agestandardised using the WHO 2013 European Standard Population, and estimated by gender, marital status and education in each cohort. Generalised linear models with a binomial family distribution and log link function calculated prevalence ratios (PRs) for probable depression and depressed affect. Multinomial logistic regression calculated odds ratios for moderate and high versus low symptom severity, which were converted into PRs. ${ }^{29}$ For each outcome, cohort-specific PRs were calculated using a onestep approach that adjusted for gender, marital status, education, plus age, age squared and self-rated health. Cohort-specific PRs by gender, marital status and education were combined to calculate pooled PRs by each determinant using random-effects metaanalysis. The $\mathrm{I}^{2}$ statistic described the proportion of betweencohort heterogeneity in associations that are not attributable to sampling variation.

In addition, we tested whether population density modified the associations described earlier in the subsample of six cohorts using two-way interaction terms between each determinant and population density. Effects were assessed for every 1000 increase in residents per square kilometre in all cohorts except for HUNT, where effects were quantified for every 10 residents per square kilometre since the maximum population density was 32 residents per square kilometre.

Cohort-specific analyses and meta-analyses were conducted using R Studio and Stata 15, respectively. CLSA analyses incorporated sampling weights to reflect the Canadian population aged $45-85$ years. $^{15}$

\section{RESULTS}

Women comprised over half of the cohort samples, except in RECORD (36.2\%) (table 1). The share of unmarried/noncohabitating adults ranged from $16.2 \%$ (HUNT) to $36.3 \%$ (LASA-1). Adults having low education ranged from $29 \%$ in CLSA to $88 \%$ in LASA-1, reflecting generational differences in formal education as these cohorts were born in 1960 or earlier, and 1942 or earlier, respectively. Age-standardised prevalence of probable depression and depressed affect in the Lithuanian and Russian HAPIEE cohorts ranged from $29.1 \%$ to $32.3 \%$ and from $18.8 \%$ to $34.1 \%$, respectively, compared to $<5 \%$ in HUNT. Urbanicity was highest in RECORD as half of the sample lived in areas with 10829 residents per square kilometre. Median population density ranged from 4700 to 5200 in the LASA cohorts, and fell to 2000 and $1000 \mathrm{~km}^{2}$ residents in HAPIEE-CZ and CLSA, respectively. Population density was remarkably low in HUNT with a median of 13 residents per square kilometre.

\section{Differences in age-standardised prevalence of depressive symptoms}

Women, unmarried/non-cohabitating adults and adults with low educational attainment reported a greater prevalence of probable depression, depressed affect (table 2) and depressive symptom 
Table 1 Study-specific characteristics of analytic cohort samples

\begin{tabular}{|c|c|c|c|c|c|c|c|c|}
\hline \multirow[b]{2}{*}{ Main analytic sample ( $\mathrm{n=97} 826)$} & \multicolumn{8}{|c|}{ Country and cohort } \\
\hline & $\begin{array}{l}\text { CA } \\
\text { CLSA }\end{array}$ & $\begin{array}{l}\text { NO } \\
\text { HUNT }\end{array}$ & $\begin{array}{l}\text { RU } \\
\text { HAPIEE }\end{array}$ & $\begin{array}{l}\text { CZ } \\
\text { HAPIEE }\end{array}$ & $\begin{array}{l}\text { LT } \\
\text { HAPIEE }\end{array}$ & $\begin{array}{l}\text { FR } \\
\text { RECORD }\end{array}$ & $\begin{array}{l}\text { NL } \\
\text { LASA-1 }\end{array}$ & $\begin{array}{l}\text { NL } \\
\text { LASA-2 }\end{array}$ \\
\hline Number of participants & 45782 & 23571 & 7766 & 6726 & 6239 & 3706 & 3041 & 995 \\
\hline Data collection wave (year) & $\begin{array}{l}\text { Wave } 1 \\
(2010-2015)\end{array}$ & $\begin{array}{l}\text { Wave } 2 \\
(1995-1997)\end{array}$ & $\begin{array}{l}\text { Wave } 1 \\
(2002-2005)\end{array}$ & $\begin{array}{l}\text { Wave } 1 \\
(2002-2005)\end{array}$ & $\begin{array}{l}\text { Wave } 1 \\
(2006-2008)\end{array}$ & $\begin{array}{l}\text { Wave } 1 \\
(2007-2008)\end{array}$ & $\begin{array}{l}\text { Wave } 1 \\
(1992-1993)\end{array}$ & $\begin{array}{l}\text { Wave } 1 \\
(2002-2003)\end{array}$ \\
\hline Mean years of age (SD) & $62.4(9.3)$ & $64.3(10.0)$ & $59.8(5.8)$ & $59.7(5.8)$ & $62.2(6.3)$ & $59.7(7.1)$ & $70.2(8.8)$ & $59.4(3.0)$ \\
\hline Female, \% & 51.5 & 52.9 & 53.8 & 52.7 & 54.5 & 36.2 & 51.6 & 52.6 \\
\hline Unmarried/non-cohabitating, \% & 25.9 & 15.9 & 29.1 & 24.4 & 31.2 & 33.4 & 36.3 & 20.3 \\
\hline Low education, \% & 29.1 & 72.3 & 71.5 & 86.1 & 45.4 & 54.3 & 88.5 & 78.3 \\
\hline Fair/poor self-rated health, $\%$ & 11.8 & 26.6 & 89.7 & 61.2 & 76.0 & 46.0 & 37.7 & 33.1 \\
\hline $\begin{array}{l}\text { Age-standardised prevalence of probable } \\
\text { depression, } \%\end{array}$ & 16.7 & 4.5 & 29.1 & 19.2 & 32.3 & 7.5 & 11.8 & 7.4 \\
\hline $\begin{array}{l}\text { Age-standardised prevalence of depressed } \\
\text { affect, } \%\end{array}$ & 8.5 & 2.4 & 18.8 & 8.2 & 34.1 & 14.1 & 5.0 & 2.1 \\
\hline \multicolumn{9}{|l|}{$\begin{array}{l}\text { Age-standardised prevalence of depressive } \\
\text { symptom severity, \% }\end{array}$} \\
\hline Low & 31.2 & 23.1 & 41.3 & 31.4 & 43.0 & 47.6 & 38.8 & 28.1 \\
\hline Moderate & 37.2 & 37.2 & 20.5 & 31.6 & 24.7 & 30.1 & 36.6 & 50.6 \\
\hline High & 31.6 & 39.7 & 38.2 & 37.0 & 32.3 & 22.3 & 24.6 & 21.3 \\
\hline \multicolumn{9}{|l|}{ Analytic subsample ( $n=73$ 123) } \\
\hline Number of participants & 45782 & 20566 & - & 1241 & - & 3706 & 993 & 835 \\
\hline Data collection wave (year) & $\begin{array}{l}\text { Wave } 1 \\
(2010-2015)\end{array}$ & $\begin{array}{l}\text { Wave } 3 \\
\text { (2006-2008) }\end{array}$ & - & $\begin{array}{l}\text { Wave } 2 \\
(2006-2008)\end{array}$ & - & $\begin{array}{l}\text { Wave } 1 \\
(2007-2008)\end{array}$ & $\begin{array}{l}\text { Wave } 5 \\
(2005-2006)\end{array}$ & $\begin{array}{l}\text { Wave } 2 \\
\text { (2005-2006) }\end{array}$ \\
\hline \multicolumn{9}{|l|}{ Number of residents per square kilometre } \\
\hline Mean (SD) & $\begin{array}{l}1056.8 \\
(1358.8)\end{array}$ & $14.1(8.7)$ & - & $\begin{array}{l}2030.0 \\
(1383.1)\end{array}$ & - & $\begin{array}{l}14689.9 \\
(11332.6)\end{array}$ & $\begin{array}{l}4723.9 \\
(3972.5)\end{array}$ & $\begin{array}{l}5185.3 \\
(4845.1)\end{array}$ \\
\hline 25th percentile & 82 & 8 & - & 1030 & - & 5379 & 2686 & 2786 \\
\hline 50th percentile & 476 & 13 & - & 1435 & - & 10829 & 4228 & 4494 \\
\hline 75th percentile & 1484 & 21 & - & 3251 & - & 25459 & 6018 & 6126 \\
\hline
\end{tabular}

CA, Canada; CLSA, Canadian Longitudinal Study on Aging; CZ, The Czech Republic; FR, France; HAPIEE, the Health, Alcohol and Psychosocial factors In Eastern Europe; HUNT, the Nord-Trøndelag Health Study; LASA-1, Longitudinal Aging Study Amsterdam—first cohort; LASA-2, Longitudinal Aging Study Amsterdam—second cohort; LT, Lithuania; NL, The Netherlands; NO, Norway; RECORD, the Residential Environment and CORonary heart Disease study, RU, Russia.

severity (online supplemental table S2), although the differences in prevalence by gender, marital status and education varied between cohorts.

The exception was HUNT, where high symptom severity was slightly more prevalent in men than in women. Prevalence differences among women relative to men were particularly high in HAPIEE-RU: 19\% for probable depression and high symptom severity and $12 \%$ for depressed affect.

Prevalence differences between marital/cohabitating groups were again smallest in HUNT, and greatest at over 20\% in HAPIEE-LT for probable depression and depressed affect. For high symptom severity, the differentials were high in the LASA cohorts (24-30\%) and HAPIEE-LT (24\%).

Educational inequalities were seen in all cohorts. For probable depression, prevalence differences by education were the largest in HAPIEE-LT at $20.76 \%$ in higher vs $34.91 \%$ in less educated adults.

\section{PRs of depressive symptoms}

Cohort-specific and pooled PRs in probable depression (figure 1), depressed affect (figure 2) and depressive symptom severity (online supplemental figures S2 and S3) are displayed in forest plots. After mutually adjusting for gender, marital status and education plus age and self-rated health, the PRs of depressive symptoms remained significantly higher in women, unmarried/ non-cohabitating adults and those with low education.

Overall, women were 1.48 times more likely to have probable depression than men. The pooled PRs among women were marginally higher for affect and slightly lower for high symptom severity. Cohort-specific PRs were comparable across all settings except in HUNT for probable depression and symptom severity.

Across cohorts, unmarried/non-cohabitating adults were 1.44 and 1.47 times more likely to have probable depression and depressed affect than married counterparts, respectively. The PR for high symptom severity among unmarried/noncohabitating adults was somewhat lower at 1.33 . However, marital status was weakly associated with depression risk in RECORD and HUNT, compared to other cohorts.

The combined PRs by low education ranged from 1.16 for high symptom severity to 1.29 for probable depression. Compared to cohort-specific PRs by gender and marital status, cohort-specific PRs by education were greater than 1 in all eight studies for the three outcomes.

Depressive symptom associations with education were most consistent between cohorts. Although the $\mathrm{I}^{2}$ percentage of 75.38 represented considerable cohort variation for probable depression, there was weak evidence of substantial heterogeneity for depressed affect $(65.64,95 \%$ CI 26.97 to 83.83$)$, as well as for moderate $(23.58,95 \%$ CI 0.00 to 65.02$)$ and high $(53.92,95 \%$ 
Table 2 Age-standardised study-specific prevalence of probable depression and depressed affect by gender, marital status and education

\begin{tabular}{|c|c|c|c|c|c|c|c|}
\hline \multicolumn{2}{|c|}{ Country and cohort } & Male & Female & Married/cohabitating & Not married/cohabitating & High education & Low education \\
\hline \multicolumn{8}{|c|}{ Probable depression (\%) } \\
\hline CA & CLSA & 13.51 (12.76 to 14.27$)$ & 19.50 (18.65 to 20.36$)$ & 14.06 (13.37 to 14.75$)$ & 23.65 (22.52 to 24.78 ) & 15.44 (14.77 to 16.11$)$ & 19.39 (18.26 to 20.51$)$ \\
\hline NO & HUNT & 4.35 (3.94 to 4.76$)$ & 4.63 (4.23 to 5.03$)$ & 4.25 (3.94 to 4.56$)$ & 5.22 (4.49 to 5.95$)$ & 2.79 (2.29 to 3.28$)$ & 4.98 (4.64 to 5.33 ) \\
\hline RU & HAPIEE & 19.17 (16.91 to 21.42$)$ & 37.72 (35.20 to 40.23$)$ & 24.39 (22.39 to 26.38$)$ & 40.14 (36.91 to 43.37$)$ & $23.61(20.48,26.73)$ & $31.10(29.07,33.14)$ \\
\hline $\mathrm{CZ}$ & HAPIEE & 13.85 (12.29 to 15.41$)$ & 24.69 (22.40 to 26.99$)$ & $16.30(14.89$ to 17.70$)$ & 27.67 (24.70 to 30.64$)$ & 13.82 (10.76 to 16.87$)$ & $20.11(18.65,21.58)$ \\
\hline LT & HAPIEE & 25.40 (24.18 to 26.63$)$ & 29.76 (28.19 to 31.33$)$ & 18.39 (17.19 to 19.58$)$ & 42.07 (40.10 to 44.04$)$ & 20.76 (19.36 to 22.16$)$ & 34.91 (33.39 to 36.42 ) \\
\hline FR & RECORD & $5.16(4.12$ to 6.20$)$ & 10.90 (9.10 to 12.70$)$ & 6.52 (5.45 to 7.60$)$ & 9.56 (7.51 to 11.61$)$ & 5.44 (4.13 to 6.74$)$ & 9.05 (7.66 to 10.44$)$ \\
\hline NL & LASA-1 & 8.95 (7.39 to 10.51$)$ & 14.33 (12.63 to 16.02$)$ & 8.66 (7.00 to 10.33$)$ & 23.27 (20.19 to 26.36$)$ & 10.48 (7.17 to 13.79$)$ & 11.89 (10.65 to 13.13$)$ \\
\hline NL & LASA-2 & 5.75 (4.09 to 7.42$)$ & 9.97 (8.26 to 11.68$)$ & 6.02 (4.88 to 7.15$)$ & 25.32 (19.32 to 31.33$)$ & 5.66 (3.21 to 8.11$)$ & 8.20 (6.90 to 9.51$)$ \\
\hline \multicolumn{8}{|c|}{ Depressed affect (\%) } \\
\hline CA & CLSA & 7.01 (6.47 to 7.56$)$ & 9.79 (9.13 to 10.46$)$ & 7.33 (6.83 to 7.82 ) & 11.62 (10.76 to 12.49$)$ & 7.88 (7.37 to 8.39$)$ & 9.90 (9.04 to 10.76$)$ \\
\hline NO & HUNT & 1.99 (1.73 to 2.25$)$ & 2.82 (2.51 to 3.12 ) & 2.29 (2.06 to 2.53$)$ & 3.48 (2.84 to 4.11$)$ & 1.73 (1.39 to 2.07$)$ & 2.70 (2.45 to 2.96$)$ \\
\hline $\mathrm{RU}$ & HAPIEE & $12.39(10.34$ to 14.44$)$ & 24.41 (22.08 to 26.74$)$ & 15.55 (13.78 to 17.33$)$ & 26.69 (23.62 to 29.75$)$ & $13.25(10.72,15.77)$ & 20.88 (18.99 to 22.77 ) \\
\hline $\mathrm{CZ}$ & HAPIEE & 5.60 (4.49 to 6.71$)$ & 10.63 (9.19 to 12.08$)$ & 6.60 (5.67 to 7.53$)$ & 13.10 (10.94 to 15.25$)$ & 4.73 (3.46 to 6.00$)$ & 8.84 (7.81 to 9.88$)$ \\
\hline LT & HAPIEE & 27.04 (25.76 to 28.32$)$ & 31.87 (30.27 to 33.48$)$ & 20.61 (19.36 to 21.85$)$ & 43.15 (41.17 to 45.14$)$ & 22.81 (21.36 to 24.27$)$ & 36.43 (34.90 to 37.97$)$ \\
\hline FR & RECORD & 10.05 (8.72 to 11.39$)$ & 20.14 (17.86 to 22.41$)$ & $13.38(11.93$ to 14.84$)$ & 15.72 (13.31 to 18.13$)$ & 11.25 (9.53 to 12.97$)$ & $16.26(14.51,18.02)$ \\
\hline NL & LASA-1 & 2.65 (1.91 to 3.40 ) & 7.07 (5.78 to 8.36$)$ & 2.88 (2.23 to 3.53$)$ & 11.31 (8.95 to 13.67$)$ & 2.39 (0.93 to 3.84$)$ & 5.31 (4.44 to 6.18 ) \\
\hline NL & LASA-2 & $1.38(0.53$ to 2.23$)$ & 2.98 (1.98 to 3.99$)$ & 1.51 (0.91 to 2.11$)$ & 8.60 (4.78 to 12.41$)$ & $0.60(-0.23$ to 1.43$)$ & 2.53 (1.77 to 3.30$)$ \\
\hline
\end{tabular}

CA, Canada; CLSA, Canadian Longitudinal Study on Aging; CZ, The Czech Republic; FR, France; HAPIEE, the Health, Alcohol and Psychosocial factors In Eastern Europe; HUNT, the Nord-Trøndelag Health Study; LASA-1, Longitudinal Aging Study Amsterdam—-first cohort; LASA-2, Longitudinal Aging Study Amsterdam—-second cohort; LT, Lithuania; NL, The Netherlands; NO, Norway; PR, prevalence ratio; RECORD, the Residential Environment and CORonary heart Disease study, RU, Russia.

CI; $0.00,79.22$ ) symptom severity. $\mathrm{I}^{2}$ and $95 \%$ CI percentages were well above $60 \%$ for gender and marital status, indicating extensive heterogeneity in these associations between cohorts. For probable depression, heterogeneity for gender and marital status was 92.99 (95\% CI 88.50 to 95.73$)$ and 88.26 (95\% CI 79.16 to 93.39 ), respectively.

\section{Effect modification by population density}

Table 3 reports the main effects of population density and its interactions with each determinant on probable depression and depressed affect in the subsample of six cohorts. Higher levels of population density were strongly associated with depression in CLSA. PRs of probable depression and depressed affect increased by $4 \%$ and $5 \%$ per 1000 increase in residents per square kilometre, respectively.

Higher population density modified gender and marital status inequalities in LASA-2 but not in the hypothesised direction. PRs for probable depression among women and unmarried persons decreased by $6 \%$ (PR: $0.94,95 \%$ CI 0.90 to 0.98 ) and 4\% (PR: $0.96,95 \%$ CI 0.92 to 1.00 ) for every 1000 increase in residents per square kilometre. After stratifying by population density tertiles in LASA-2, PRs were highest among older women and unmarried persons living in low-density areas, compared to higher-density areas (online supplemental figure S4). Population density did not modify inequalities in other cohorts, including the elder cohort from the same Dutch region (LASA-1). Main and interaction effects for high symptom severity were similarly weak across the six cohorts (results available upon request).

\section{DISCUSSION}

This comparative study of eight European and Canadian cohorts found broadly consistent gender, marital and educational inequalities in mid- to late-life depressive symptoms. Despite our hypothesis, there was weak evidence that population density moderated these inequalities.

\section{Strengths and limitations}

Heterogeneity in measurement of depressive symptoms across cohorts is a major concern. Depressive symptoms were retrospectively harmonised to create three indicators across cohorts using four depression scales (CES-D 20, CES-D 10, HADS-D and QD2A). Although each measured psychological, physical and social symptoms that characterise MDD, ${ }^{30}$ overlap between individual symptoms was moderate. Where same symptoms were collected, scale differences in wording may result in under- or over-reporting of symptoms. ${ }^{31}$ However, some experts have concluded that different depression scales measure depression risk in clinically meaningful ways, provided that they reliably assess the multiple dimensions that characterise depression. ${ }^{31}$ CES-D 10 has demonstrated very good prognostic accuracy in comparison to CES-D $20^{20}$ which in turn has shown to perform similarly as HADS-D. ${ }^{32}$ Although QD2A has not been examined against HADS-D or the CES-D scales, QD2A has shown a strong-tomoderate correlation with the Zung Self-Rating Depression Scale, ${ }^{24}$ which portrays a highly similar factor structure as the CES-D 20. ${ }^{33}$ Yet, these comparisons were made on specific samples, so the performance of these scales across MINDMAP cohorts is unknown. We addressed this uncertainty by testing associations using several indicators.

Probable depression is most clinically meaningful, but scalespecific thresholds for symptom scores, with different finite ranges, may have identified people with varying pathology or severity. Depressed affect has obvious face validity between studies, but it remains unclear what feeling sad, depressed or downhearted signifies. Comparing associations with a single symptom circumvents the issue that different symptoms may have different risk factors, ${ }^{34}$ and vary in their genetic background. ${ }^{35}$ Indeed, a European-wide study of older adults found that women reported a higher number of affective, but not motivational, symptoms than men. ${ }^{8}$ Nonetheless, depression is considered a latent construct, and its presence is inferred from multiple symptom domains. ${ }^{31}$ Given similar gender, marital and 


\begin{tabular}{|c|c|c|c|}
\hline Cohort & & $\mathrm{PR}(95 \% \mathrm{Cl})$ & $\begin{array}{l}\% \\
\text { Weight }\end{array}$ \\
\hline \multicolumn{4}{|l|}{ Female vs. male } \\
\hline CLSA & 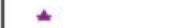 & $1.30(1.24,1.36)$ & 14.45 \\
\hline HUNT & t & $0.99(0.88,1.12)$ & 13.37 \\
\hline HAPIEE-RU & 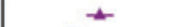 & $1.85(1.70,2.02)$ & 13.97 \\
\hline HAPIEE-CZ & 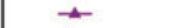 & $1.58(1.42,1.76)$ & 13.62 \\
\hline HAPIEE-LT & 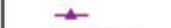 & $1.54(1.39,1.72)$ & 13.63 \\
\hline RECORD & $\longrightarrow$ & $1.87(1.48,2.36)$ & 10.77 \\
\hline LASA-1 & $\longrightarrow$ & $1.28(1.06,1.54)$ & 11.91 \\
\hline LASA-2 & $\longrightarrow$ & $1.93(1.37,2.71)$ & 8.28 \\
\hline I-squared $=92.99 \%(88.50,95.73)$ & 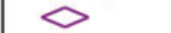 & $1.48(1.28,1.72)$ & 100.00 \\
\hline \multicolumn{4}{|c|}{ Not married/cohabitating vs. married/cohabitating } \\
\hline CLSA & 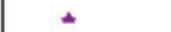 & $1.52(1.45,1.59)$ & 15.83 \\
\hline HUNT & $\leftarrow$ & $1.16(0.99,1.35)$ & 12.40 \\
\hline HAPIEE-RU & $\perp$ & $1.31(1.22,1.41)$ & 15.23 \\
\hline HAPIEE-CZ & 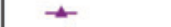 & $1.45(1.31,1.60)$ & 14.40 \\
\hline HAPIEE-LT & $\leftarrow$ & $1.51(1.38,1.66)$ & 14.64 \\
\hline RECORD & - & $0.87(0.68,1.12)$ & 9.00 \\
\hline LASA-1 & $\hookrightarrow$ & $2.23(1.84,2.70)$ & 11.01 \\
\hline LASA-2 & $\longrightarrow$ & $1.97(1.46,2.66)$ & 7.50 \\
\hline I-squared $=88.26 \%(79.16,93.39)$ & $\diamond$ & $1.44(1.29,1.61)$ & 100.00 \\
\hline \multicolumn{4}{|l|}{ Low education vs. high education } \\
\hline CLSA & & $1.14(1.09,1.19)$ & 20.45 \\
\hline HUNT & 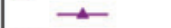 & $1.66(1.41,1.95)$ & 12.88 \\
\hline HAPIEE-RU & 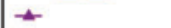 & $1.18(1.08,1.28)$ & 18.13 \\
\hline HAPIEE-CZ & $\rightarrow$ & $1.30(1.09,1.54)$ & 12.22 \\
\hline HAPIEE-LT & 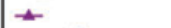 & $1.18(1.08,1.29)$ & 17.88 \\
\hline RECORD & $\longrightarrow$ & $1.60(1.25,2.05)$ & 8.42 \\
\hline LASA-1 & 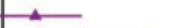 & $1.23(0.91,1.65)$ & 6.62 \\
\hline LASA-2 & $\longrightarrow$ & $1.65(1.04,2.60)$ & 3.40 \\
\hline I-squared $=75.38 \%(50.51,87.75)$ & $\diamond$ & $1.29(1.18,1.41)$ & 100.00 \\
\hline \multicolumn{4}{|c|}{ NOTE: Weights are from random effects analysis } \\
\hline$T$ & & & \\
\hline .25 & $i$ & & \\
\hline & ment & & \\
\hline
\end{tabular}

Figure 1 Forest plot of study-specific and pooled prevalence ratios $(95 \% \mathrm{Cls}$ ) for probable depression by gender, marital status and education. CLSA, Canadian Longitudinal Study on Aging; CZ, The Czech Republic; HAPIEE, the Health, Alcohol and Psychosocial factors In Eastern Europe; HUNT, the Nord-Trøndelag Health Study; LASA-1, Longitudinal Aging Study Amsterdam—first cohort; LASA-2, Longitudinal Aging Study Amsterdam—second cohort; LT, Lithuania; PR, prevalence ratio; RECORD, the Residential Environment and CORonary heart Disease study, RU, Russia.

\begin{tabular}{|c|c|c|c|}
\hline Cohort & & $\mathrm{PR}(95 \% \mathrm{Cl})$ & $\begin{array}{l}\% \\
\text { Weight }\end{array}$ \\
\hline \multicolumn{4}{|l|}{ Female vs. male } \\
\hline CLSA & $\rightarrow$ & $1.30(1.21,1.40)$ & 16.23 \\
\hline HUNT & $\rightarrow$ & $1.30(1.10,1.53)$ & 13.68 \\
\hline HAPIEE-RU & $\rightarrow$ & $1.94(1.73,2.18)$ & 15.19 \\
\hline HAPIEE-CZ & $\rightarrow$ & $1.84(1.54,2.20)$ & 13.25 \\
\hline HAPIEE-LT & $\rightarrow$ & $1.52(1.38,1.68)$ & 15.65 \\
\hline RECORD & $\rightarrow$ & $1.80(1.53,2.11)$ & 13.82 \\
\hline LASA-1 & $\longrightarrow$ & $1.78(1.30,2.44)$ & 9.03 \\
\hline LASA-2 & & $2.12(1.05,4.30)$ & 3.14 \\
\hline I-squared $=85.62 \%(73.61,92.16)$ & $>$ & $1.62(1.41,1.86)$ & 100.00 \\
\hline \multicolumn{4}{|c|}{ Not married/cohabitating vs. married/cohabitating } \\
\hline CLSA & $\rightarrow$ & $1.51(1.41,1.63)$ & 15.98 \\
\hline HUNT & $\rightarrow$ & $1.43(1.17,1.75)$ & 12.43 \\
\hline HAPIEE-RU & $\rightarrow$ & $1.30(1.17 .1 .44)$ & 15.29 \\
\hline HAPIEE-CZ & $\rightarrow$ & $1.72(1.46,2.02)$ & 13.64 \\
\hline HAPIEE-LT & $\rightarrow$ & $1.42(1.30,1.54)$ & 15.73 \\
\hline RECORD & & $0.90(0.76,1.06)$ & 13.52 \\
\hline LASA-1 & $\longrightarrow$ & $2.40(1.76,3.28)$ & 9.17 \\
\hline LASA-2 & & $2.68(1.49,4.84)$ & 4.24 \\
\hline I-squared $=87.30 \%(77.17,92.94)$ & & $1.47(1.28,1.70)$ & 100.00 \\
\hline \multicolumn{4}{|l|}{ Low education vs. high education } \\
\hline CLSA & $\rightarrow$ & $1.13(1.05,1.21)$ & 22.25 \\
\hline HUNT & $\longrightarrow$ & $1.43(1.17,1.75)$ & 12.06 \\
\hline HAPIEE-RU & $\rightarrow$ & $1.35(1.20,1.52)$ & 18.34 \\
\hline HAPIEE-CZ & $\longrightarrow$ & $1.38(1.04,1.83)$ & 8.00 \\
\hline HAPIEE-LT & $\rightarrow$ & $1.17(1.08,1.27)$ & 21.46 \\
\hline RECORD & $\rightarrow$ & $1.28(1.09,1.51)$ & 14.71 \\
\hline LASA-1 & - & $1.96(1.08,3.56)$ & 2.38 \\
\hline LASA-2 & & $4.80(1.16,9.83)$ & 0.79 \\
\hline I-squared $=65.64 \%(26.97,83.83)$ & $\diamond$ & $1.28(1.17,1.41)$ & 100.00 \\
\hline \multicolumn{4}{|c|}{ NOTE: Weights are from random effects analysis } \\
\hline$T$ & & & \\
\hline .25 & 1 & & \\
\hline
\end{tabular}

Figure 2 Forest plot of study-specific and pooled prevalence ratios (95\% Cls) for depressed affect by gender, marital status and education. CLSA, Canadian Longitudinal Study on Aging; CZ, The Czech Republic; HAPIEE, the Health, Alcohol and Psychosocial factors In Eastern Europe; HUNT, the Nord-Trøndelag Health Study; LASA-1, Longitudinal Aging Study Amsterdam—first cohort; LASA-2, Longitudinal Aging Study Amsterdam—second cohort; LT, Lithuania; PR, prevalence ratio; RECORD, the Residential Environment and CORonary heart Disease study, RU, Russia. 
Table 3 Study-specific main effects of population density and interactions with gender, marital status and education on the risk of probable depression and depressed affect

\begin{tabular}{|c|c|c|c|c|c|}
\hline \multicolumn{2}{|c|}{ Country and cohort } & $\begin{array}{l}\text { PR }(95 \% \mathrm{Cl}) \text { per } 1000 \text { residents } \\
\text { per square kilometre* }\end{array}$ & $\begin{array}{l}\text { Interaction between gender and } \\
\text { population densityt }\end{array}$ & $\begin{array}{l}\text { Interaction between marital } \\
\text { status and population density }\end{array}$ & $\begin{array}{l}\text { Interaction between education } \\
\text { and population densityt }\end{array}$ \\
\hline \multicolumn{6}{|c|}{ PRs for probable depression $(95 \% \mathrm{CI})$} \\
\hline CA & CLSA & 1.04 (1.02 to 1.05$)$ & $\begin{array}{l}0.99(0.96 \text { to } 1.02) \\
p=0.36\end{array}$ & $\begin{array}{l}1.01(0.98 \text { to } 1.04) \\
p=0.55\end{array}$ & $\begin{array}{l}1.02(0.99 \text { to } 1.05) \\
p=0.15\end{array}$ \\
\hline NO & HUNT‡ & $0.76(0.68$ to 0.85$)$ & $\begin{array}{l}0.97(0.78 \text { to } 1.20) \\
p=0.76\end{array}$ & $\begin{array}{l}1.05(0.81 \text { to } 1.35) \\
p=0.73\end{array}$ & $\begin{array}{l}0.95(0.76 \text { to } 1.19) \\
p=0.68\end{array}$ \\
\hline $\mathrm{CZ}$ & HAPIEE & $0.93(0.82$ to 1.06$)$ & $\begin{array}{l}0.99(0.73 \text { to } 1.34) \\
p=0.96\end{array}$ & $\begin{array}{l}0.88(0.66 \text { to } 1.17) \\
p=0.39\end{array}$ & $\begin{array}{l}1.20(0.78 \text { to } 1.84) \\
p=0.40\end{array}$ \\
\hline FR & RECORD & $1.00(0.99$ to 1.01$)$ & $\begin{array}{l}0.9(0.97 \text { to } 1.02) \\
p=0.63\end{array}$ & $\begin{array}{l}1.00(0.98 \text { to } 1.02) \\
p=0.82\end{array}$ & $\begin{array}{l}0.99(0.97 \text { to } 1.02) \\
p=0.55\end{array}$ \\
\hline NL & LASA-1 & $1.00(0.97$ to 1.03$)$ & $\begin{array}{l}0.98(0.91 \text { to } 1.05) \\
p=0.51\end{array}$ & $\begin{array}{l}1.04(0.98 \text { to } 1.12) \\
p=0.20\end{array}$ & $\begin{array}{l}1.05(0.93 \text { to } 1.19) \\
p=0.44\end{array}$ \\
\hline NL & LASA-2 & $1.02(0.99$ to 1.05$)$ & $\begin{array}{l}0.94(0.90 \text { to } 0.98) \\
p<0.01\end{array}$ & $\begin{array}{l}0.96(0.92 \text { to } 1.00) \\
p=0.07\end{array}$ & $\begin{array}{l}0.98(0.92 \text { to } 1.05) \\
p=0.57\end{array}$ \\
\hline \multicolumn{6}{|c|}{ PRs for depressed affect $(95 \% \mathrm{Cl})$} \\
\hline $\mathrm{CA}$ & CLSA & 1.05 (1.03 to 1.08$)$ & $\begin{array}{l}0.98(0.93 \text { to } 1.02) \\
p=0.34\end{array}$ & $\begin{array}{l}0.99(0.95 \text { to } 1.04) \\
p=0.76\end{array}$ & $\begin{array}{l}1.02(0.97 \text { to } 1.07) \\
p=0.42\end{array}$ \\
\hline NO & HUNT‡ & $0.96(0.88$ to 1.04$)$ & $\begin{array}{l}1.05(0.88 \text { to } 1.24) \\
p=0.59\end{array}$ & $\begin{array}{l}0.95(0.78 \text { to } 1.17) \\
p=0.66\end{array}$ & $\begin{array}{l}1.08(0.91 \text { to } 1.27) \\
p=0.40\end{array}$ \\
\hline $\mathrm{CZ}$ & HAPIEE & $0.95(0.85$ to 1.06$)$ & $\begin{array}{l}1.12(0.86 \text { to } 1.46) \\
p=0.41\end{array}$ & $\begin{array}{l}0.89(0.69 \text { to } 1.16) \\
p=0.40\end{array}$ & $\begin{array}{l}1.08(0.75 \text { to } 1.57) \\
p=0.66\end{array}$ \\
\hline FR & RECORD & $1.00(0.99$ to 1.01$)$ & $\begin{array}{l}1.00(0.99 \text { to } 1.02) \\
p=0.64\end{array}$ & $\begin{array}{l}1.00(0.98 \text { to } 1.01) \\
p=0.71\end{array}$ & $\begin{array}{l}1.00(0.99 \text { to } 1.01) \\
p=0.98\end{array}$ \\
\hline $\mathrm{NL}$ & LASA-1 & $1.00(0.94$ to 1.06$)$ & $\begin{array}{l}0.97(0.86 \text { to } 1.11) \\
p=0.69\end{array}$ & $\begin{array}{l}1.04(0.93 \text { to } 1.17) \\
p=0.48\end{array}$ & $\begin{array}{l}1.01(0.84 \text { to } 1.21) \\
p=0.94\end{array}$ \\
\hline $\mathrm{NL}$ & LASA-2 & $0.95(0.87$ to 1.03$)$ & $\begin{array}{l}1.01(0.84 \text { to } 1.22) \\
p=0.93\end{array}$ & $\begin{array}{l}0.99(0.82 \text { to } 1.20) \\
p=0.94\end{array}$ & $\begin{array}{l}0.90(0.76 \text { to } 1.06) \\
p=0.20\end{array}$ \\
\hline
\end{tabular}

*The main effect of population density (per 1000 residents per square kilometre) was adjusted for all three determinants plus age, age squared and self-rated health.

tInteraction effects between population density and each exposure were adjusted for the other two exposures plus age, age squared and self-rated health.

$\ddagger$ The HUNT analyses were based on 10 residents per square kilometre because the maximum population density value was 32 residents per square kilometre in the analytic sample.

CA, Canada; CLSA, Canadian Longitudinal Study on Aging; CZ, The Czech Republic; FR, France; HAPIEE, the Health, Alcohol and Psychosocial factors In Eastern Europe; HUNT, the Nord-Trøndelag Health Study; LASA-1, Longitudinal Aging Study Amsterdam—first cohort; LASA-2, Longitudinal Aging Study Amsterdam—second cohort; LT, Lithuania; NL, The Netherlands; NO, Norway; PR, prevalence ratio; RECORD, the Residential Environment and CORonary heart Disease study, RU, Russia.

educational inequalities across outcomes, these contentious issues may be waived aside for the present study.

Since population density data at the area level were unavailable for HAPIEE-LT and HAPIEE-RU, we could not explore the moderating hypothesis across the full range of urban settings captured by MINDMAP. Population density appears to have limited capacity to capture important aspects of the urban environment, which may be important for depression. Indeed, health researchers have urged the development of urbanicity scales drawing on a range of reliable measures. ${ }^{13}$ Unfortunately, more nuanced urbanicity measures were unavailable across cohorts at this stage of the project. Furthermore, cross-cohort findings may be influenced by cohort and period effects since participants were studied from 1992-1993 (LASA-1) to 2010-2015 (CLSA). Despite this time span, the magnitude of cross-cohort inequalities aligns with several European reports which used concurrent data between countries, ${ }^{6-8}$ suggesting that depression inequalities may be robust to broad secular changes.

\section{Consistency with existing evidence}

The magnitude of depression inequalities found across MINDMAP studies is remarkably consistent with high-quality evidence from several reviews. ${ }^{3-5} \mathrm{~A}$ meta-analysis of five prospective studies reported that community-dwelling women aged $\geq 50$ years have a 1.4 higher odds of depression than men, but stated weaker pooled
ORs of 1.0 (95\% CI 0.8 to 1.3 ) and 1.5 (95\% CI 0.8 to 2.8 ) by marital status and education, respectively. ${ }^{3}$ Larger systematic reviews and meta-analyses of cross-sectional and prospective studies on adults aged $\geq 55$ years, however, found increased risks associated with never married (relative risk (RR) 1.32) and widowed (RR 1.49) statuses $^{4}$ as well as with low education (OR 1.58 ) on prevalent depression. ${ }^{5}$ Although we analysed self-reported symptoms in the absence of clinically diagnosed cases, considered to be more valid measures of depressive disorders, ${ }^{36}$ our findings demonstrate that the MINDMAP-harmonised data set is a solid resource for comparative ageing and mental well-being research. ${ }^{14}$

In a study of adults aged $\geq 50$ years from Northern, Western and Southern Europe, PRs for probable depression, measured by the European Depression (EURO-D) scale, risks among females were lowest in Denmark (1.91) and higher in Spain (3.89). PRs comparing low to high educational groups varied widely from 1.70 (Greece) to 3.02 (France). ${ }^{7}$ Among adults aged $\geq 65$ years from similar parts of Europe, never married, widowed and divorced/separated adults reported a higher number of depressive symptoms than married adults, but only in 9 of 13 sites. ${ }^{8}$ Few European studies on mid- to late-life depression included Central and Eastern Europe (CEE), but larger gender ${ }^{6}$ and educational ${ }^{37}$ inequalities have been reported in CEE than in Northern countries including Norway, among adults aged $18-75^{6}$ and 60-80 years, ${ }^{37}$ respectively. Altogether, these comparative findings ${ }^{6-837}$ align with the cross-cohort variation of depression 
inequalities reported in our study. Since these studies measured depressive symptoms using a single scale across countries, ${ }^{6-8} 37$ this provides further support that cross-cohort variation in MINDMAP is not driven by the abovementioned measurement issues.

Our study found that population density was weakly associated with depression, and consequently did not modify the strong effects of gender, marital status and education on depression. Although the higher depression risk among older adults in urban versus rural areas is well established, ${ }^{2}$ there is limited and mixed evidence of a graded increase in depression by increasing population density. ${ }^{3839}$ Probable depression risk among women and unmarried/non-cohabitating adults decreased in higherdensity areas in LASA-2. This could indicate greater convergence within private or social life between men and women ${ }^{6}$ and greater social integration of older single persons ${ }^{8}$ with higher levels of urbanicity. Since these results were not replicated in other cohorts, including LASA-1, which consisted of adults born decades earlier from the same regions, the LASA-2 results may be due to confounding or selection biases. Despite some ecological correlation between population density and depression inequalities, both of which were lower in HUNT than in other cohorts, inequalities within cohorts were unmodified by densification, suggesting that people's position in society are 'fundamental causes' of inequalities irrespective of the social context. $^{40}$

\section{CONCLUSION}

Given strong mid- to late-life depression inequalities amidst increasing rates of urbanicity in Europe and Canada, future work should assess the interplay between putative risk factors and specific urban municipal-level determinants and living conditions, ${ }^{9}$ which may influence older adults' mental health.

\section{What is already known on this subject}

- Gender, marital and educational inequalities in mid- to late-life depression are well established, but the magnitude of these inequalities may vary between European and North American countries due to differences in urbanicity.

- The share of older European and North American adults residing in cities has grown exponentially over the last several decades. Living in more densely populated cities may exacerbate depression risks associated with female gender, unmarried/ divorced/widowed status and low educational attainment.

- This study hypothesised that increasing levels of population density, a marker of urbanicity, would magnify mid- to late-life depression inequalities.

\section{What this study adds}

- This comparative study of European and Canadian ageing cohorts found strong gender, marital and educational inequalities in depressive symptoms, and the magnitude varied between cohorts.

- However, population density, measured by the number of residents per square kilometre, was weakly associated with depression risk across cohorts, and thus did not modify depression inequalities.

\section{Author affiliations}

${ }^{1}$ Research Department of Epidemiology and Public Health, University College London, London, UK

${ }^{2}$ Department of Public Health, Erasmus University Medical Center, Rotterdam, Netherlands

${ }^{3}$ Research Institute of the McGill University Health Centre, Montreal, Canada

${ }^{4}$ Department of Health Research Methods, Evidence and Impact, McMaster University, Hamilton, Ontario, Canada

${ }^{5}$ McMaster Institute for Research on Aging, Hamilton, Ontario, Canada

${ }^{6}$ Department of Epidemiology and Biostatistics, Amsterdam UMC, VU University

Medical Center, Amsterdam Public Health Research Institute, Amsterdam,

Netherlands

${ }^{7}$ Sorbonne Université, INSERM, Institut Pierre Louis d'Epidémiologie et de Santé

Publique, Nemesis Research Team, Paris, France

${ }^{8}$ Department of Sociology, Faculty of Social Sciences, Vrije Universiteit Amsterdam, Amsterdam, Netherlands

${ }^{9}$ HUNT Research Centre, Department of Public Health and General Practice, Faculty of Medicine, Norwegian University of Science and Technology (NTNU), Levanger, Norway

${ }^{10}$ Levanger Hospital, Nord-Trøndelag Hospital Trust, Levanger, Norway

${ }^{11}$ Centre for Environmental Health Monitoring, National Institute of Public Health,

Prague, Czech Republic

${ }^{12}$ Research Institute of Internal and Preventive Medicine, Branch of the Institute of Cytology and Genetics, SB RAS, Novosibirsk, Russia

${ }^{13}$ Novosibirsk State Medical University, Novosibirsk, Russia

${ }^{14}$ Institute of Cardiology, Academy of Medicine, Lithuanian University of Health

Sciences, Kaunas, Lithuania

${ }^{15}$ Faculty of Public Health, Academy of Medicine, Lithuanian University of Health

Sciences, Kaunas, Lithuania

${ }^{16}$ Department of Human Geography and Spatial Planning, Utrecht University, Utrecht, Netherlands

Acknowledgements The authors are grateful to Professor Mauricio Avendano for critical review of the manuscript and many helpful comments. MAR and MBO are also grateful to Professor Michael Dewey, Dr Lauren Griffith, Professor Scott Hofer and Dr Graciela Muniz-Terrera for their invaluable input and expertise on the harmonisation of the depressive symptomatology data. PR holds the Raymond and Margaret Labarge Chair in Optimal Aging and Knowledge Application for Optimal Aging, is the Director of the McMaster Institute for Research on Aging and the Labarge Centre for Mobility in Aging, and holds a Tier 1 Canada Research Chair in Geroscience.

Contributors MAR co-designed the study, conducted all analyses, drafted the initial and revised manuscript, and approved the final manuscript as submitted. MBo codesigned the study, finalised the initial and revised manuscript, and approved the final manuscript as submitted. BC and FJvL contributed to the design of the study. All coauthors critically reviewed the manuscript and approved the final manuscript as submitted.

Funding This study is supported by a European Commission Horizon 2020 Grant, 667661, as part of the Promoting Mental Well-being in the Ageing Population: Determinants, Policies and Interventions in European Cities (MINDMAP) research project. This research was made possible using the data/ biospecimens collected by the Canadian Longitudinal Study on Aging (CLSA). Funding for the CLSA is provided by the Government of Canada through the Canadian Institutes of Health Research (CIHR) under grant reference: LSA 94473 and the Canada Foundation for Innovation. This research has been conducted using the CLSA data set, Baseline Comprehensive Dataset version 4.0, under application number 171013. The CLSA is led by Drs Parminder Raina, Christina Wolfson and Susan Kirkland. The Nord-Trøndelag Health Study (HUNT) is mainly funded by the Norwegian Ministry of Health (NTNU), with additional support from the Norwegian Research Council (the FUGE programme), Central Norway Regional Health Authority, the Nord-Trøndelag County Council and the Norwegian Institute of Public Health. The Health, Alcohol and Psychosocial factors In Eastern Europe (HAPIEE) study is funded by the Wellcome Trust (grants 064947 and 081081), the US National Institute on Aging (grant R01 AG23522-01), the MacArthur Foundation 'MacArthur Initiative on Social Upheaval and Health' (grant 712058). The Longitudinal Aging Study Amsterdam (LASA) is largely supported by grants from the Netherlands Ministry of Health, Welfare and Sports, Directorate of Long-Term Care. The Residential Environment and CORonary heart Disease (RECORD) study is supported by INPES (National Institute for Prevention and Health Education); IReSP (Institute for Public Health Research); InVS (National Institute of Public Health Surveillance); French Ministries of Research and Health; CNAM-TS (National Health Insurance Office for Salaried Workers); and the Ile-de-France Regional Health Agency (ARS). MAB's work was funded by a Netherlands Organization for Scientific Research (NWO) VENI grant on 'DenCityHealth: How to keep growing urban populations healthy?' (grant 09150161810158). 


\section{Competing interests None declared.}

Patient consent for publication Not required.

Ethics approval All participating cohort studies have originally received consent from the participants and ethical approval from their respected institutions: CLSA has received ethical approval from the Hamilton Integrated Research Ethics Board. HUNT received ethical approval from the Regional Committee for Medical Research Ethics, Mid-Norway. In addition, MINDMAP-specific approval was received from the same committee. HAPIEE received ethical approval from the Joint UCL/UCLH Committees on the Ethics of Human Research, and by local ethics committees in every participating centre. RECORD received ethical approval from the Commission Nationale de I'Informatique et des Libertés. LASA received ethical approval by the Medical Ethical Committee of the Vrije Universiteit medisch centrum. Secondary use of the MINDMAP harmonised data set also received a declaration of no objection from the Medical Ethical Committee of Erasmus University Medical Centre.

Provenance and peer review Not commissioned; externally peer reviewed.

Data availability statement The data sets generated for the MINDMAP project are not publicly available due to study participant privacy considerations. However, data access can be requested from the individual cohort studies via the respective data access procedures in place. Data are available from the Canadian Longitudinal Study on Aging (www.clsa-elcv.ca) for researchers who meet the criteria for access to de-identified CLSA data.

Supplemental material This content has been supplied by the author(s). It has not been vetted by BMJ Publishing Group Limited (BMJ) and may not have been peer-reviewed. Any opinions or recommendations discussed are solely those of the author(s) and are not endorsed by BMJ. BMJ disclaims all liability and responsibility arising from any reliance placed on the content. Where the content includes any translated material, BMJ does not warrant the accuracy and reliability of the translations (including but not limited to local regulations, clinical guidelines, terminology, drug names and drug dosages), and is not responsible for any error and/or omissions arising from translation and adaptation or otherwise.

Open access This is an open access article distributed in accordance with the Creative Commons Attribution 4.0 Unported (CC BY 4.0) license, which permits others to copy, redistribute, remix, transform and build upon this work for any purpose, provided the original work is properly cited, a link to the licence is given, and indication of whether changes were made. See: https://creativecommons.org/licenses/ by/4.0\%.

\section{ORCID iDs}

Milagros A Ruiz http://orcid.org/0000-0001-7492-9873

Erik J Timmermans http://orcid.org/0000-0002-3414-7196

Steinar Krokstad http://orcid.org/0000-0002-2932-6675

\section{REFERENCES}

1 Ferrari AJ, Charlson FJ, Norman RE, et al. Burden of depressive disorders by country, sex, age, and year: findings from the global burden of disease study 2010. PLoS Med 2013;10:e1001547.

2 Purtle J, Nelson KL, Yang Y, et al. Urban-rural differences in older adult depression: a systematic review and meta-analysis of comparative studies. Am J Prev Med 2019:56:603-13

3 Cole MG, Dendukuri N. Risk factors for depression among elderly community subjects: a systematic review and meta-analysis. Am J Psychiat 2003:160:1147-56.

4 Yan $X Y$, Huang SM, Huang CQ, et al. Marital status and risk for late life depression: a meta-analysis of the published literature. J Int Med Res 2011;39:1142-54.

5 Chang-Quan $\mathrm{H}$, Zheng-Rong W, Yong-Hong L, et al. Education and risk for late life depression: a meta-analysis of published literature. Int I Psychiatry Med 2010:40:109-24

6 Van de Velde S, Bracke P, Levecque K. Gender differences in depression in 23 European countries. Cross-national variation in the gender gap in depression. Soc Sci Med 2010;71:305-13.

7 Castro-Costa E, Dewey M, Stewart R, et al. Prevalence of depressive symptoms and syndromes in later life in ten European countries: the SHARE study. Br I Psychiatry 2007;191:393-401

8 Prince MJ, Beekman AT, Deeg DJ, et al. Depression symptoms in late life assessed using the EURO-D scale. Effect of age, gender and marital status in 14 European centres. $\mathrm{Br}$ J Psychiatry 1999:174:339-45.

9 Vlahov D, Galea S. Urbanization, urbanicity, and health. J Urban Health 2002;79:S1-s12.

10 OECD. Ageing in cities. Paris: OECD Publishing, 2015.
11 Dustmann C, Fasani F. The effect of local area crime on mental health. Econ J 2016:126:978-1017.

12 Hoare E, Jacka F, Berk M. The impact of urbanization on mood disorders: an update of recent evidence. Curr Opin Psychiatry 2019:32:198-203.

13 Cyril S, Oldroyd JC, Renzaho A. Urbanisation, urbanicity, and health: a systematic review of the reliability and validity of urbanicity scales. BMC Public Health 2013:13:513.

14 Beenackers MA, Doiron D, Fortier I, et al. MINDMAP: establishing an integrated database infrastructure for research in ageing, mental well-being, and the urban environment. BMC Public Health 2018;18:158.

15 Raina PS, Wolfson C, Kirkland SA, et al. The Canadian longitudinal study on aging (CLSA). Can J Aging 2009;28:221-9.

16 Krokstad S, Langhammer A, Hveem K, et al. Cohort profile: the HUNT study, Norway. Int J Epidemiol 2013;42:968-77.

17 Peasey A, Bobak M, Kubinova R, et al. Determinants of cardiovascular disease and other non-communicable diseases in Central and Eastern Europe: rationale and design of the HAPIEE study. BMC Public Health 2006;6:255-55.

18 Chaix B, Kestens Y, Bean $\mathrm{K}$, et al. Cohort profile: residential and non-residential environments, individual activity spaces and cardiovascular risk factors and diseases-the RECORD Cohort Study. Int J Epidemiol 2011:41:1283-92.

19 Huisman M, Poppelaars J, van der Horst M, et al. Cohort profile: the Longitudinal Aging Study Amsterdam. Int J Epidemiol 2011;40:868-76.

20 Andresen EM, Malmgren JA, Carter WB, et al. Screening for depression in well older adults: evaluation of a short form of the CES-D (Center for Epidemiologic Studies Depression Scale). Am J Prev Med 1994;10:77-84.

21 Irwin $\mathrm{M}$, Artin KH, Oxman MN. Screening for depression in the older adult: criterion validity of the 10-item Center for Epidemiological Studies Depression Scale (CES-D). Arch Intern Med 1999;159:1701-4.

22 Radloff LS. The Center for Epidemiologic Studies Depression Scale: a self-report depression scale for research in the general population. Appl Psychol Meas 1977;1:385-401.

23 Zigmond AS, Snaith RP. The Hospital Anxiety and Depression Scale. Acta Psychiatry Scand 1983:67:361-70.

24 Pichot P. A self-report inventory on depressive symptomatology (QD2) and its abridged form (QD2A). In: Sartorius N, Ban TA, eds. Assessment of depression. Berlin Heidelberg: Springer Berlin Heidelberg, 1986: 108-22.

25 Weissman MM, Sholomskas D, Pottenger M, et al. Assessing depressive symptoms in five psychiatric populations: a validation study. Am J Epidemiol 1977;106:203-14.

26 Snaith RP. The Hospital Anxiety and Depression Scale. Health Qual Life Outcomes 2003:1:29.

27 UNESCO. The International Classification of Education ISCED 2011. Montreal: UNESCO Institute for Statistics, 2012: 1-88.

28 Spitzer S, Weber D. Reporting biases in self-assessed physical and cognitive health status of older Europeans. PLoS One 2019;14:e0223526.

29 Fox J, Hong J. Effect displays in R for multinomial and proportional-odds logit models: extensions to the effects package. J Stat Software 2009;32:24.

30 Fried El. The 52 symptoms of major depression: lack of content overlap among seven common depression scales. J Affect Disord 2017:208:191-7.

31 McClintock S, Haley C, Bernstein I. Psychometric considerations of depression symptom rating scales. Neuropsychiatry 2011;1:611-23.

32 Macedo EA, Appenzeller S, Costallat LTL. Depression in systemic lupus erythematosus: gender differences in the performance of the Beck Depression Inventory (BDI), Center for Epidemiologic Studies Depression Scale (CES-D), and Hospital Anxiety and Depression Scale (HADS). Lupus 2018;27:179-89.

33 Shafer AB. Meta-analysis of the factor structures of four depression questionnaires: Beck, CES-D, Hamilton, and Zung. J Clin Psychol 2006;62:123-46.

34 Fried El, Nesse RM, Zivin K, et al. Depression is more than the sum score of its parts: individual DSM symptoms have different risk factors. Psychol Med 2014;44:2067-76.

35 Flint J, Kendler KS. The genetics of major depression. Neuron 2014;81:484-503.

36 Comstock GW, Helsing KJ. Symptoms of depression in two communities. Psychol Med 1977;6:551-63.

37 Hansen T, Slagsvold B, Veenstra M. Educational inequalities in late-life depression across Europe: results from the generations and gender survey. Eur J Ageing 2017;14:407-18

38 Generaal E, Hoogendijk EO, Stam M, et al. Neighbourhood characteristics and prevalence and severity of depression: pooled analysis of eight Dutch cohort studies. $\mathrm{Br}$ J Psychiatry 2019;215:468-75.

39 Motoc I, Timmermans EJ, Deeg D, et al. Associations of neighbourhood sociodemographic characteristics with depressive and anxiety symptoms in older age: results from a 5-wave study over 15 years. Health Place 2019;59:102172.

40 Beckfield J, Olafsdottir S, Bakhtiari E. Health inequalities in global context. Am Behav Sci 2013;57:1014-39. 